\title{
THE TREATMENT OF HYPERTROPHIC EMPHYSEMA BY PNEUMOPERITONEUM
}

\author{
BY \\ BERTRAM MANN AND EDMOND A. MURPHY \\ From the Royal Halifax Infirmary
}

(RECEIVED FOR PUBLICATION JULY 25, 1953)

One of the commonest medical conditions encountered in general practice and in chest clinics is hypertrophic emphysema. An analysis of the last 500 consecutive patients with chest symptoms attending the Halifax Chest Clinic was made, and no fewer than $75(15 \%)$ were found to be suffering from this disease, with or without chronic bronchitis. Sixty-four of these were men and 11 were women; three-quarters of them were in the fifth and sixth decades, the most economically productive period of their lives. Clearly any form of treatment which can improve this serious condition deserves careful investigation.

In hypertrophic emphysema there is a substantial reduction in the effective area of respiratory exchange, expiration is impossible passively, and the excursion of the low flattened diaphragm on inspiration is limited or absent. Later, secondary skeletal changes, such as kyphosis and fixity of, and increase in, circumference of the thorax further limit respiration. Physiotherapeutic exercises designed to educate the accessory muscles of respiration are often used to improve the expiratory phase. Donald (1953), however, questions their value. As long ago as 1936, Alexander devised a pressure-belt which, applied to the lower abdomen, helped to relieve the dyspnoea; but symptomatic relief did not always accompany the improvement in the vital capacity which he noted.

Several investigators have recommended the induction of pneumoperitoneum to "arch" the diaphragm by positive intraperitoneal pressure, which artificially permits passive expiration. Rubin and Gass (1948) and Monaldi (1937) have reported that bronchospasm is relieved and expectoration rendered less exhausting by pneumoperitoneum.

Reich (1924) appears to have been the first to use pneumoperitoneum in emphysema, but the method fell into disuse until the work of Piaggio Blanco, R. A., Piaggio Blanco, R. O., and Caimi (1937). Recently others have reported favourably on its use (Carter, Gaensler, and Kyllonen, 1950;
Furman and Callaway, 1950; Brackenridge and Jones, 1953). Callaway and McKusick (1951) found it very useful for a patient with emphysema who had been comatose for three days from carbon dioxide poisoning associated with oxygen administration.

In view of these favourable reports, we decided to attempt a controlled investigation of the effect of pneumoperitoneum on a small series of patients suffering from hypertrophic emphysema. There are many pitfalls in the assessment of clinical improvement in emphysema. While subjective benefit is important, it can be greatly influenced by suggestion; and even objective signs are affected by the well-known variations in respiratory function produced by bronchospasm, intercurrent infection, emotion, weather, season, etc. We therefore decided to investigate 10 cases of long-standing, progressive, advanced emphysema, in such a way that each patient provided his own " control." Of the 10 patients, nine were male and one female: their ages ranged from 38 to 69 (average 53) years. All had completed a course of three months' breathing exercises with a trained physiotherapist.

Vital capacity is an index of comparatively little value in estimating pulmonary function. Often, in emphysema, it may reach a high level, but only at the expense of prolonged expiration. Furman and Callaway (1950) attempted to obviate this difficulty by limiting the expiratory phase to three seconds. Maximum breathing capacity is a more valuable yardstick, measuring the effective " turnover" of the lung at full effort during a stipulated period of time.

The patients were instructed in the use of the Benedict-Roth spirometer, and when they were accustomed to it three vital capacity and three maximum breathing capacity readings were taken, with an adequate period of rest between each reading to avoid fatigue. At attempt was then made to estimate the degree of bronchospasm. The patient inhaled 12 breaths of nebulized 1:100 isopropyl 
noradrenaline; after five minutes' rest, the inhalations were repeated, and after another period of rest three further recordings of the vital capacity and maximum breathing capacity were made. The results are summarized in Table I. In at least two cases the improvement in lung function was considerable, and in four others it was appreciable. The negative results may be a fatigue phenomenon.

TABLE I

THE EFFECT OF ISOPROPYL NORADRENALINE ON VITAL AND MAXIMUM BREATHING CAPACITIES

\begin{tabular}{|c|c|c|c|c|c|c|}
\hline \multirow[b]{2}{*}{ Case } & \multicolumn{3}{|c|}{ Vital Capacity } & \multicolumn{3}{|c|}{ Maximum Breathing Capacity } \\
\hline & $\begin{array}{c}\text { Average } \\
\text { Normal } \\
\text { (ml.) }\end{array}$ & $\begin{array}{c}\begin{array}{c}\text { Average } \\
\text { After } \\
\text { Inhalations } \\
\text { (ml.) }\end{array} \\
\end{array}$ & $\begin{array}{c}\text { Per- } \\
\text { centage } \\
\begin{array}{c}\text { Improve- } \\
\text { ment }\end{array}\end{array}$ & $\begin{array}{c}\text { Average } \\
\text { Normal } \\
\text { (1./min.) }\end{array}$ & $\begin{array}{c}\text { Average } \\
\text { After } \\
\text { Inhalations } \\
\text { (1./min.) }\end{array}$ & $\begin{array}{c}\text { Per- } \\
\text { centage } \\
\text { Improve- } \\
\text { ment }\end{array}$ \\
\hline $\begin{array}{r}1 \\
2 \\
3 \\
4 \\
5 \\
6 \\
7 \\
8 \\
9 \\
10\end{array}$ & $\begin{array}{r}1,200 \\
2,065 \\
2,200 \\
1,700 \\
2,100 \\
2,365 \\
1,485 \\
2,385 \\
650 \\
1,635\end{array}$ & $\begin{array}{l}1,200 \\
2,000 \\
2,365 \\
2,065 \\
2,085 \\
2,535 \\
1,975 \\
2,535\end{array}$ & $\begin{array}{r}00 \\
-3.2 \\
7.5 \\
21.5 \\
-0.7 \\
7.2 \\
33.0 \\
6.3\end{array}$ & $\begin{array}{l}20 \cdot 63 \\
30.54 \\
32.70 \\
32.62 \\
47.18 \\
55.55 \\
20.95 \\
30.40 \\
16.10 \\
30.23\end{array}$ & $\begin{array}{l}23.23 \\
32.00 \\
32.37 \\
35.13 \\
44.08 \\
66.32 \\
20.95 \\
34.20 \\
19.73 \\
28.85\end{array}$ & $\begin{array}{r}126 \\
4.8 \\
-1.0 \\
7.7 \\
-6.6 \\
19.4 \\
0.0 \\
12.5 \\
22.5 \\
-4.6\end{array}$ \\
\hline
\end{tabular}

An artificial pneumoperitoneum was then induced and refills were given weekly over a period of three months. During this period three readings each of vital capacity and maximum breathing capacity were taken at monthly intervals, two days after a refill. Patients were interrogated about changes in the degree of their dyspnoea, the quantity of sputum, and the effort required for expectoration. Fluoroscopy was performed weekly both before and after each refill. It was soon found that a large pneumoperitoneum might result in aggravation of dyspnoea. A diaphragmatic elevation of $1 \frac{1}{2}$ in. $(3.7 \mathrm{~cm}$.) regulated by screen markers was easily tolerated and occasioned no discomfort. The average volume of air introduced weekly was $300-550 \mathrm{ml}$., the final pressure being approximately $4 \cdot 0-8 \cdot 0 \mathrm{~cm}$. of water.

To assess the response of emphysema to pneumoperitoneum treatment, adequate control observations are essential in view of the known fluctuations mentioned above. If a small series is to be of value, it must be arranged that each patient provides his own control. The pneumoperitoneum was therefore abandoned without the patient's knowledge; the needle was still inserted every week, a mock pneumoperitoneum being given. When fluoroscopy showed that the air had all been absorbed, the maximum breathing capacity and vital capacity readings were repeated. As pneumoperitoneum treatment in the majority of our cases was begun in summer, and was due for abandonment in
October and November, a certain deterioration in respiratory function tests could have arisen from seasonal influence and intercurrent infections. To meet this criticism, the pneumoperitoneum was re-induced, and further tracings taken after a period of one month. Finally the pneumoperitoneum was again replaced by mock refills, and when the air had all absorbed a final set of maximum breathing capacity and vital capacity readings were taken.

Of our series of 10 patients, one developed congestive failure and subsequently died. Pneumoperitoneum treatment had to be abandoned in two patients; in one because of bleeding from a peptic ulcer, and in the other because of congestive cardiac failure. In these cases, the results are necessarily incomplete.

\section{RESULTS}

VITAL CAPACITY.-Although the vital capacity is a poor test of respiratory function, we have analysed the results in Table II. A striking improvement was observed in the early stages in Case 9, and there was a moderate improvement in Case 1, especially in the later stages. In Cases 2, 4, and 7, only slight benefit was recorded. Cases 3,6 , and 8 appear to be unaffected, while 5 and 10 are actually worse. Except in Cases 1 and 9, these variations might be attributed to variation in the weather and the presence or absence of respiratory infection.

TABLE II

THE EFFECT OF PNEUMOPERITONEUM ON THE VITAL CAPACITY

\begin{tabular}{|c|c|c|c|c|c|}
\hline Case & $\begin{array}{c}\text { Before } \\
\text { (ml.) }\end{array}$ & $\begin{array}{l}\text { With } \\
\text { (ml.) }\end{array}$ & $\begin{array}{c}\text { After } \\
\text { Abandoned } \\
\text { (ml.) }\end{array}$ & $\begin{array}{l}\text { After } \\
\text { Reinduced } \\
\text { (ml.) }\end{array}$ & $\begin{array}{c}\text { After Final } \\
\text { Abandon- } \\
\text { ment } \\
\text { (ml.) }\end{array}$ \\
\hline $\begin{array}{r}1 \\
2 \\
3 \\
4 \\
5 \\
6 \\
7 \\
8 \\
9 \\
10\end{array}$ & $\begin{array}{r}1,200 \\
2,065 \\
2,200 \\
1,700 \\
2,100 \\
2,365 \\
1,485 \\
2,385 \\
650 \\
1,635\end{array}$ & $\begin{array}{l}1,230 \\
2,310 \\
2,275 \\
1,975 \\
1,750 \\
2,335 \\
2,010 \\
2,345 \\
2,010 \\
1,350\end{array}$ & $\begin{array}{c}1,215 \\
2,265 \\
2,135 \\
1,885 \\
1,685 \\
1,985 \\
2,025 \\
1,825 \\
1,300 \\
-\end{array}$ & $\begin{array}{c}1,440 \\
2,385 \\
1,950 \\
\overline{1,750} \\
2,215 \\
2,315 \\
\overline{1,015} \\
-\end{array}$ & $\begin{array}{l}1,200 \\
2,115 \\
1,900 \\
1,535 \\
2,200 \\
2,150 \\
1,085 \\
-\end{array}$ \\
\hline
\end{tabular}

Averages of all the figures available are taken.

The Maximum Breathing Capacity.-At first sight it would appear that there is considerable improvement in the maximum breathing capacity following pneumoperitoneum in several of our cases (Table III). Closer examination, however, reveals a constant improvement in only one (Case 1). Very slight benefit is apparent in Case 2 and in the later stages of Case 5. Since pneumoperitoneum was not re-induced in Cases 4 and 8 , we consider the results to be indeterminate, though we formed 
TABLE III

THE EFFECT OF PNEUMOPERITONEUM ON THE MAXIMUM BREATHING CAPACITY

\begin{tabular}{|c|c|c|c|c|c|c|c|c|c|c|}
\hline \multirow[b]{2}{*}{ Case } & \multirow[b]{2}{*}{ Before } & \multicolumn{9}{|c|}{ Monthly Readings } \\
\hline & & \multicolumn{4}{|c|}{$\begin{array}{c}\text { With } \\
\text { Pneumoperitoneum }\end{array}$} & \multicolumn{2}{|c|}{$\begin{array}{c}\text { After First } \\
\text { Abandonment }\end{array}$} & \multicolumn{2}{|c|}{$\begin{array}{c}\text { With } \\
\text { Re-induction }\end{array}$} & $\begin{array}{c}\text { After } \\
\text { Final } \\
\text { Abandon- }\end{array}$ \\
\hline $\begin{array}{r}1 \\
2 \\
3 \\
4 \\
5 \\
6 \\
7 \\
8 \\
9 \\
10\end{array}$ & $\begin{array}{l}20 \cdot 63 \\
30 \cdot 54 \\
32.70 \\
32 \cdot 62 \\
47 \cdot 18 \\
55 \cdot 55 \\
20.95 \\
30 \cdot 40 \\
16 \cdot 10 \\
30 \cdot 23\end{array}$ & $\begin{array}{l}26 \cdot 63 \\
57 \cdot 10 \\
35 \cdot 80 \\
32 \cdot 17 \\
42 \cdot 52 \\
66 \cdot 35 \\
19 \cdot 13 \\
31 \cdot 57 \\
22 \cdot 53 \\
22 \cdot 49\end{array}$ & $\begin{array}{l}27 \cdot 82 \\
43 \cdot 10 \\
41 \cdot 05 \\
28 \cdot 97 \\
38 \cdot 55 \\
55 \cdot 53 \\
26 \cdot 55 \\
35 \cdot 80 \\
22 \cdot 08 \\
29 \cdot 35\end{array}$ & $\begin{array}{l}24 \cdot 48 \\
4487 \\
40 \cdot 18 \\
55 \cdot 90 \\
33 \cdot 41 \\
35 \cdot 25 \\
31 \cdot 34\end{array}$ & $\begin{array}{l}33 \cdot 17 \\
30 \cdot 98\end{array}$ & $\begin{array}{l}24.43 \\
50.20 \\
46.07 \\
31.05 \\
32.63 \\
53.92 \\
32.10 \\
31.52 \\
26.53\end{array}$ & $\begin{array}{l}32 \cdot 58 \\
36 \cdot 80 \\
22 \cdot 60\end{array}$ & $\begin{array}{l}37.85 \\
53.02 \\
37.97 \\
\\
37.17 \\
59 \cdot 28 \\
34.40 \\
23.77\end{array}$ & $\begin{array}{l}34 \cdot 87 \\
47 \cdot 98\end{array}$ & $\begin{array}{l}24 \cdot 33 \\
52 \cdot 23 \\
46 \cdot 13 \\
\\
32.65 \\
62.41 \\
39.75\end{array}$ \\
\hline
\end{tabular}

Average of three readings (litres per minute)

the impression that Case 8 did derive some genuine benefit, since his condition deteriorated rapidly when pneumoperitoneum was abandoned. The remaining five cases showed no real improvement, though in four of them $(3,6,7$, and 9) the last recorded figures are better than those taken before treatment. This may well be due to improved efficiency in performing the test. This is well illustrated in Case 7, presented graphically in Fig. 1 ;

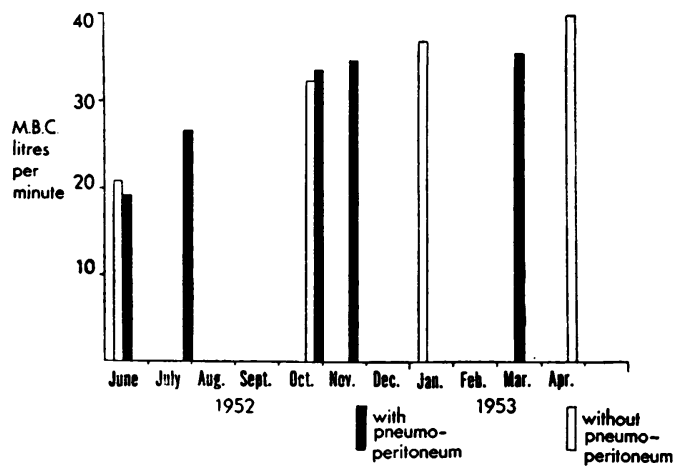

FIG. 1.-The relationship betwee 1 the M.B.C. and the pressure or absence of pneumoperitoneum in Case 7 .

with slight deviations, there is a steady increase in the maximum breathing capacity over a period of 10 months whether a pneumoperitoneum is present or not. The figures for Case 10 are incomplete, but no improvement was found during the period of observation.

Correlation between the Vital and Maximum BREATHING CAPACITY.-As expected, this proved to be low, but it is interesting that while a high vital capacity with a low maximum breathing capacity was common, the converse did not occur; in other words, while a low vital capacity indicated poor ventilatory function, the converse does not hold.
The Symptomatic Response.-Changes in symp. toms during treatment are summarized in Table IV.

TABLE IV

CLINICAL STATE IN RELATION TO PNEUMOPERITONEUM

\begin{tabular}{|c|c|c|c|c|}
\hline Case & $\begin{array}{c}\text { With } \\
\text { Pneumo- } \\
\text { peritoneum }\end{array}$ & $\begin{array}{c}\text { After First } \\
\text { Abandon- } \\
\text { ment }\end{array}$ & $\begin{array}{l}\text { After } \\
\text { Re-induc- } \\
\text { tion }\end{array}$ & $\begin{array}{c}\text { After Final } \\
\text { Abandon- } \\
\text { ment }\end{array}$ \\
\hline $\begin{array}{r}1 \\
2 \\
3 \\
4 \\
5 \\
6 \\
7 \\
8 \\
9 \\
10\end{array}$ & $\begin{array}{l}\text { Good } \\
\text { Bä } \\
\text { Variable } \\
\text { Good } \\
\text { " } \\
\dddot{y} \\
\text { Fair } \\
\text { Bad }\end{array}$ & $\begin{array}{l}\text { Fair } \\
\text { Bad } \\
\text { Variable } \\
\text { Good } \\
\text { Bad } \\
\text { Good } \\
\text { Bad } \\
\text { " }\end{array}$ & $\begin{array}{l}\text { Good } \\
\text { Bad } \\
\text { Good } \\
\text { Bad } \\
\text { Good } \\
\overline{\text { Bad }}\end{array}$ & $\begin{array}{l}\text { Very bad } \\
\text { Bad good } \\
\text { Good } \\
\text { Bad } \\
\text { Good } \\
\text { Bad - }\end{array}$ \\
\hline
\end{tabular}

Only in Case 1 was the patient consistently better with pneumoperitoneum and worse without it. In Cases 2, 6, 8, and 9 the first abandonment of the pneumoperitoneum was associated with some deterioration of the symptoms, but in Cases 6 and 9 there was no improvement on re-induction, and in Case 2 there was further improvement even after the pneumoperitoneum was finally abandoned. We think that in Case 8 the symptomatic benefit was due to the pneumoperitoneum in view of his marked deterioration after the pneumoperitoneum was abandoned, although the data are incomplete. Cases 3, 4, 5, and 7 appeared to be equally good (or bad) whether pneumoperitoneum was present or not and Case 10 was, if anything, made worse by it.

\section{Discussion}

These results emphasize the importance of providing adequate controls in investigations of the treatment of emphysema in order to eliminate the effect of extraneous factors. Among these prolonged experience in the use of the spirometer on the maximum breathing capacity is important. 
Symptomatic improvement is a very unsatisfactory measure of the value of treatment. Patients often have surprisingly short memories, and the effect of suggestion is hard to exclude. Nevertheless, improvement in their patient's condition is often claimed from mainly subjective considerations. Thus Smart, Davenport, and Pearson (1952) investigating a different method of treatment record no pre-treatment readings of the vital capacity and maximum breathing capacity in some of their cases.

The work of Furman and Callaway (1950) and Brackenridge and Jones (1953) is also in our opinion inconclusive. Admittedly the latter workers and also Carter and others (1950) used other criteria (e.g., diaphragmatic excursion, efficiency of take-up of oxygen by the lungs, and exercise tolerance), but most of these are indirect measurements of pulmonary function. Moreover, none of these writers continued their measurements after the pneumoperitoneum had been abandoned.

In six of our 10 cases, the values for the patients' maximum breathing capacity after final abandonment of the pneumoperitoneum are higher than at the outset, and this improvement occurred in some cases after the pneumoperitoneum had been abandoned. Even if this improvement in maximum breathing capacity mirrors a genuine functional improvement it cannot be attributed to the effect of " arching" the diaphragm, since abandonment of the pneumoperitoneum produced no deterioration of the patients' breathing, except in Case 1. It may be that the pneumoperitoneum "rests" the lung and allows it to recover some of its elasticity. Carter and others (1950) suggest that the pneumoperitoneum probably slows the rate at which degeneration occurs, and Reich (1924) noted that there was some improvement in respiratory posture after pneumoperitoneum had been discontinued. It is difficult to see how either of these factors could cause an actual improvement in respiratory function, especially as our patients had all had breathing exercises for months before treatment was started.
We feel compelled to adopt the alternative explanation, that the improvement is spurious, that is, that the patients' lungs do not function more effectively, but that the patients become more adept in performing the test, and that spontaneous seasonal variations may be responsible for part of the improvement. For example, Case 9 had much bronchospasm in spring time (see Table I), but very little during the winter.

We conclude that the results have been on the whole disappointing, and do not warrant the amount of labour and time involved in giving weekly refills. It is only fair to record that we introduced smaller volumes of air into the peritoneum than have been recommended by others, as we found that volumes of $800 \mathrm{ml}$. or over often aggravated dyspnoea in cases of hypertrophic emphysema.

\section{SUMMARY}

Maximum breathing capacity and vital capacity were recorded in 10 very advanced cases of emphysema during a period of 11 months, before, during, and after abandonment of pneumoperitoneum. Only one patient was consistently improved symptomatically and in maximum breathing capacity during the presence of the pneumoperitoneum.

The favourable results reported by other investigators are probably attributable to extraneous influences on pulmonary function and to increased efficiency and mental coordination in the performance of these tests.

We would like to thank Dr. John Eastwood for his assistance with Fig. 1.

\section{REFERENCES}

Alexander, H. L. (1936). Int. Clin., 46 ser., 4, 211

Brackenridge, R. D. C., and Jones, A. T. (1953). Brit. med. J., 1, 1135 Callaway, J. J., and McKusick, V. A. (1951). New Engl. J. Med., 245, 9.

Carter, M. G., Gaensler, E. A., and Kyllonen, A. (1950). Ibid., 243, 549.

Donald, K. W. (1953). Brit. med. J., 1, 415.

Furman, R. H and Callaway, J. J. (1950). Dis. Chest, 18, 232.

Monaldi, E. (1937). Rev. argent. Tuberc., 3, 161 .

Piaggio Blanco, R. A., Piaggio Blanco, R. O., and Caimi, R. A. (1937). Arch. urug. Med., 10, 273.

Reich, L. (1924). Wien. Arch. inn. Med., 8, 245.

Rubin, J. H., and Gass, G. D. (1948). Canad. med. Ass. J., 59, 162. O

Smart, R. H., Davenport, C. K., and Pearson, G. W. (1952). J. N Amer. med. Ass., 150, 1385. 